\title{
A rare presentation of Takayasu's arteritis- unilateral finger clubbing - case report
}

\author{
Shania Niromi Gunasekera* ${ }^{*}$, Chirath Madurapperuma, Nilusha Weerasooriya, Harindra Karunathilake and \\ Ananda Jayanaga
}

\begin{abstract}
Background: Takayasu's arteritis (TA) is a granulomatous, large vessel vasculitis with a preponderance for young women. The inflammation results in disruption of the arterial endothelium causing stenosis, endoluminal thrombosis and aneurismal dilatation. Early disease presentation is with nonspecific general symptoms, and in such instances, the diagnosis can be missed. Unilateral clubbing is a manifestation of myriad of diseases, but is not a common sign of TA. In medical literature, only three such cases have been reported.
\end{abstract}

Case presentation: We present a 24-year-old female who presented with multiple constitutional symptoms such as arthralgia, malaise, poor appetite and two episodes of syncope over 3 months' duration. On examination, unilateral finger clubbing was observed in the right hand, with very low volume radial, ulnar and brachial artery pulses on the ipsilateral side. Her blood pressure measured on the unaffected arm, was normal. Inflammatory markers were elevated and magnetic resonance angiogram (MRA) confirmed TA.

Conclusion: Although rare, unilateral clubbing may be a manifestation of TA. Therefore, detection of unilateral clubbing should raise a strong clinical suspicion of TA and prompt early diagnosis and initiation of treatment.

Keywords: Takayasu's arteritis, Large vessel vasculitis, Unilateral clubbing , Case report

\section{Background}

Takayasu's arteritis (TA) is a granulomatous arteritis involving large vessels, predominantly the aorta and its major branches [1]. Inflammation of the arteries causing endothelial damage can lead to vessel wall thickening, vascular occlusion and thrombus formation [2]. The resultant ischemia may cause disabling symptoms. Early in the disease, symptoms are nonspecific, such as fever, fatigue, arthralgia, myalgia and weight loss, and in such instances, the diagnosis is often missed [2].

We present a case of Takayasu's arteritis, presenting with constitutional symptoms and unilateral finger clubbing. Only three similar cases have been reported in the literature [3-5].

* Correspondence: shania.g89@gmail.com National Hospital of Sri Lanka, Colombo 08, Sri Lanka

\section{Case presentation}

A 24-year-old female from Southern province of Sri Lanka, presented with arthralgia, malaise and poor appetite for 3 months' duration. A week prior to the admission, she had an episode of transient loss of consciousness, which was followed by an uneventful recovery. It was assumed to be a vasovagal syncope, since the semiology was not suggestive of a seizure and it was not associated with chest pain or palpitations. She had a similar event a month ago, which also resolved spontaneously upon lying down.

She complained of arthralgia involving all small and large joints indiscriminately without any signs of inflammation. She did not give a history of fever, chills or rigors, drenching night sweats or weight loss. She denied cough, difficulty in breathing, chest pain, headache, visual disturbances, photophobia, or photosensitive rashes. She also did not have cold intolerance, constipation,

(c) The Author(s). 2020 Open Access This article is licensed under a Creative Commons Attribution 4.0 International License, which permits use, sharing, adaptation, distribution and reproduction in any medium or format, as long as you give appropriate credit to the original author(s) and the source, provide a link to the Creative Commons licence, and indicate if changes were made. The images or other third party material in this article are included in the article's Creative Commons licence, unless indicated otherwise in a credit line to the material. If material is not included in the article's Creative Commons licence and your intended use is not permitted by statutory regulation or exceeds the permitted use, you will need to obtain permission directly from the copyright holder. To view a copy of this licence, visit http://creativecommons.org/licenses/by/4.0/. The Creative Commons Public Domain Dedication waiver (http://creativecommons.org/publicdomain/zero/1.0/) applies to the data made available in this article, unless otherwise stated in a credit line to the data. 
menorrhagia, polyuria or polydipsia. She denied neck pain, limb claudication or Raynaud's phenomenon. She was not on any medications. She had regular menstrual periods. She had no premorbid illnesses and her family history was unremarkable.

On examination, her height was $144 \mathrm{~cm}$ and she weighed $42 \mathrm{~kg}$ with a body mass index of $21 \mathrm{~kg} / \mathrm{m} 2$. She was not febrile or pale and there was no hair loss, rashes, oral or genital ulcers. She did not have redness in the eyes. She had grade 2 clubbing involving the fingers of the right hand (Fig. 1a, b). Interestingly, clubbing was absent in the fingers of the left hand and toes of both feet. Her radial, ulnar and brachial pulses were barely felt in the right arm, whereas in the left arm, all the pulses were felt with normal volume. Blood pressure was not recordable in the right arm and in the left, it was $112 / 88 \mathrm{mmHg}$. The carotid and femoral pulses were palpable in normal volume and there was no radio-radial or radio-femoral delay. Mild tenderness was elicited over the right carotid artery but, there was no bruit. Cardiac examination was normal. Lung fields were clear. Rest of the examination was unremarkable.

Full blood count revealed neutrophil leukocytosis, mild normocytic normochromic anemia and thrombocytosis.

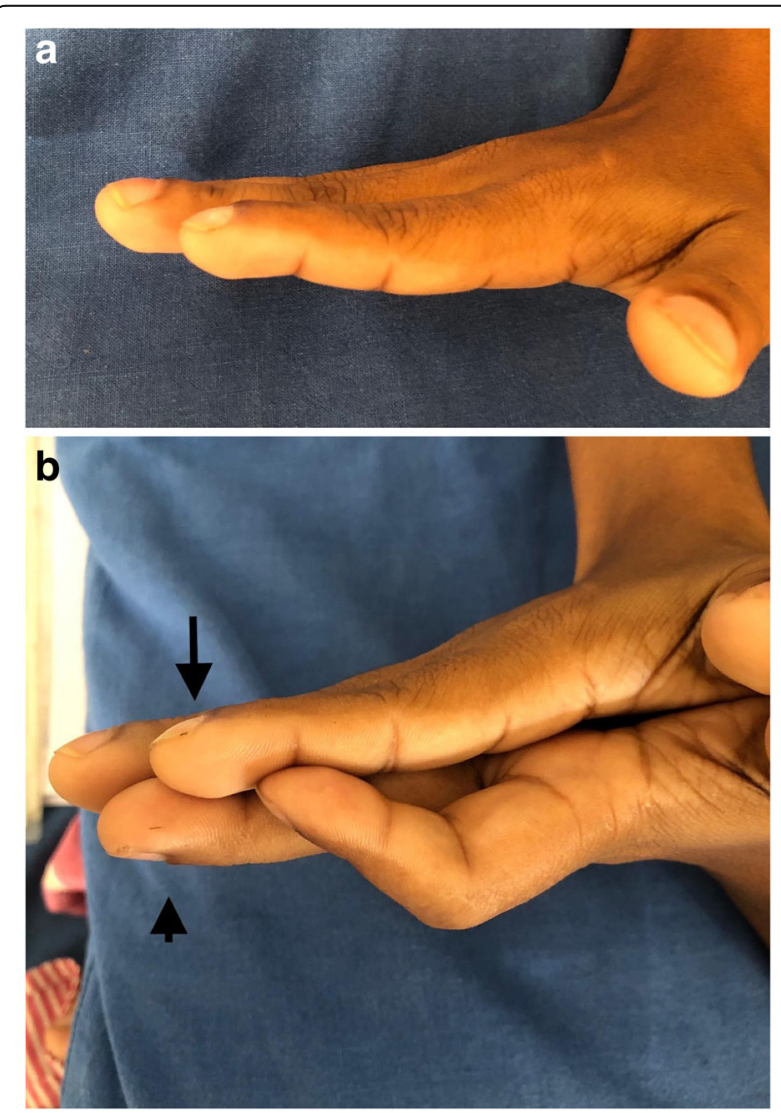

Fig. 1 a Right hand finger clubbing. $\mathbf{b}$ - right side unilateral finger clubbing (arrow)with sparing of left hand fingers (arrow head)
Her erythrocyte sedimentation rate (ESR) was $>110$ $\mathrm{mm} / 1$ st hour and C-reactive protein (CRP) was 24 $\mathrm{mmol} / \mathrm{l}$. Liver and renal functions, serum electrolytes including calcium and magnesium, and thyroid functions were normal. The chest and spine X-ray images failed to show any abnormalities. Computed tomography (CT) aortogram revealed thrombosis of brachio-cephalic trunk, right common carotid, subclavian and axillary arteries.

Her clotting studies, including prothrombin time, thrombin time and activated partial thrombin time were normal. Anti-thrombin iii, Protein $\mathrm{C}$ and Protein $\mathrm{S}$ levels were normal, thereby excluding common diseases of thrombophilia. Anti-cardiolipin IgM antibody, Lupus anticoagulant, anti Beta 2 glycoprotein IgG and IgM antibodies were negative. Anti nuclear antibody (ANA), anti double stranded DNA (anti ds DNA), cytoplasmic anti neutrophil cytoplasmic antibodies (ANCA) and perinuclear ANCA, were all negative.

Magnetic Resonance angiogram (MRA) was performed to further delineate the cause for thrombosis. In the MRA, brachio-cephalic artery was completely occluded at it's origin. There were collateral vessels, formed distal to the brachio cephalic stump (Fig. 2).

Considering the clinical presentation, elevated inflammatory markers and MR angiographic evidence, TA involving the brachio-cephalic artery and its branches was diagnosed.

She was given intravenous methylprednisolone $500 \mathrm{mg}$ daily for 3 days followed by oral prednisolone $40 \mathrm{mg}$ daily. Oral Azathioprin $50 \mathrm{mg}$ daily was added as a steroid sparing agent. She was anticoagulated, initially with subcutaneous enoxaparin followed by warfarin $4 \mathrm{mg}$, daily.

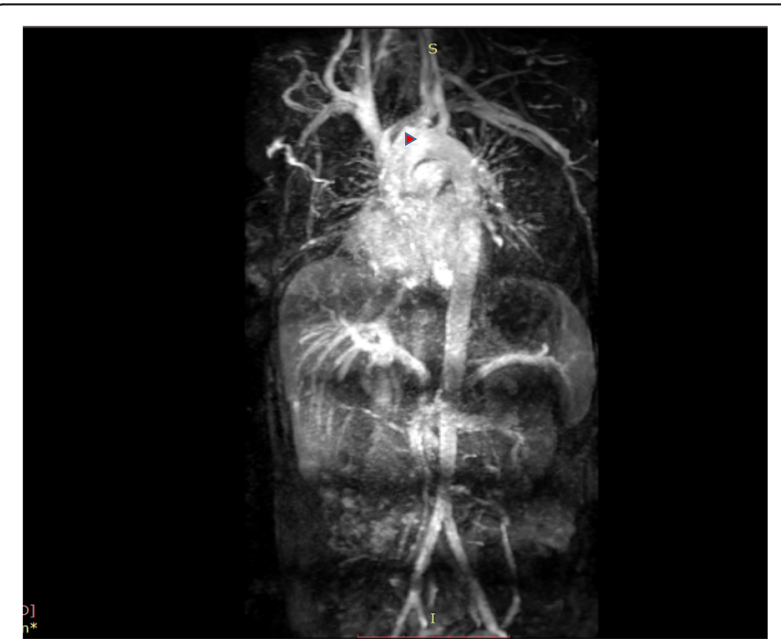

Fig. 2 MR angiogram of aorta and its branches - the brachiocephalic trunk is obliterated at it's origin (arrow head) 
After starting the treatment, her symptoms subsided and 3 months in to the therapy, clubbing still persisted. ESR reduced to 35 and she is currently being followed up monthly, at our clinic.

\section{Discussion}

TA is an autoimmune, chronic, granulomatous vasculitis involving the large arteries. Inflammation of the endothelium causes stenosis, thrombosis, luminal occlusion and aneurysmal dilatation [2]. TA has a preponderance for females, accounting for over $90 \%$ of the cases. The incidence of TA is highest in the fourth decade [6]. The etiology of TA has not been fully understood but a genetic basis has been described. Certain infections, particularly Mycobacterial tuberculosis has been linked to the pathogenesis of TA [1].

Early symptoms include headaches, fever, weight loss, myalgia, and arthralgia. Hypertension is common, which occurs in $80 \%$ of cases due to stenosis of the renal arteries resulting in activation of reninangiotensin- aldosterone system [1]. Hypertension was absent in this patient, probably because of her early presentation before the renal arteries were involved. The classic features of TA such as limb claudication, carotid or subclavian arterial bruits and end organ ischemia, which usually occur as the disease progresses, were absent in this patient.

Markers of inflammation such as ESR and CRP are elevated in most, but not all patients with TA. The elevated CRP level correlates with thrombotic events [1].

European league against Rheumatism (EULAR) recommends MR angiogram as the first imaging modality to detect vessel wall inflammation and changes [7]. Positron emission tomography (PET) scan, when combined with CT shows diffuse hypermetabolism of the involved arteries and enables evaluation of wall thickness and luminal changes. However, its cost, availability and exposure to high dose of radiation limit its use [8].

The index case fulfilled 4 out of 6 ACR criteria (Table 1). In the initial stages nonspecific symptoms predominate. Hence, the diagnosis is often missed. In our patient, the initial clue to the diagnosis was unilateral finger clubbing. There are only three similar cases reported in the literature [3-5].

Finger clubbing can be associated with a multitude of diseases and unilateral finger clubbing has been reported with hemiplegia, dialysis fistulae, arteritis of the large arteries, and ulna artery aneurysm [10]. The pathogenesis of digital clubbing is best explained by the hypothesis put foreword by Dickinson and Martin [11]. They proposed that, when
Table 1 The diagnostic criteria for TA coined by American College of Rheumatology (ACR) [9]

\begin{tabular}{|c|c|}
\hline & $\begin{array}{l}\text { diagnosis is most likely when three or more out of the } \\
\text { owing six criteria are met }\end{array}$ \\
\hline & age of onset younger than 40 years \\
\hline & claudication of extremities \\
\hline & decreased pulsation of one or both brachial arteries \\
\hline & difference of systolic pressure between arms at least by $10 \mathrm{mmHg}$ \\
\hline & bruits over one or both subclavian arteries or the abdominal aorta \\
\hline & $\begin{array}{l}\text { arteriography showing narrowing or occlusion of the entire aorta, its } \\
\text { primary branches, or large arteries in the proximal upper or lower } \\
\text { extremities not cause by arteriosclerosis, fibromuscular dysplasia, or } \\
\text { other causes }\end{array}$ \\
\hline
\end{tabular}

unfragmented megakaryocytes enter the systemic circulation through A-V malformations, their large size make them stagnate in the fingertip circulation causing local tissue hypoxia. This in turn induces the release of platelet-derived growth factor (PDGF), causing increased vascular permeability, number of vascular smooth muscle cells and fibroblasts [11]. Atkinson and Fox proposed that vascular endothelial growth factor (VEGF) and hypoxia inducible factor (HIF), which are released in response to tissue hypoxia, also played a synergistic role with PDGF, in the pathogenesis of digital clubbing [12]. Though this hypothesis does not entirely explain the unilateral finger clubbing in our patient, severe arteritis with rapidly progressive stenosis and the resultant local hypoxia would have triggered the aforementioned pathological process. Clubbing, at its early stage may reverse with treatment of the causative disease, but not so if it has become chronic [10].

The EULAR 2018 guideline for the management of large-vessel vasculitis recommends initiation of high dose corticosteroid therapy at the point of diagnosis. A steroid sparing immunosuppressant should be added if corticosteroids alone fail to achieve and maintain remission. Tocilizumab, a TNF -alfa inhibitor can be considered in treating recalcitrant disease. Regular antiplatelet or anticoagulation is indicated when organ threatening ischemia is evident. In our patient, anticoagulation was commenced as she had a large thrombus occluding the right common carotid artery, which may have been the cause for the two episodes of syncope.

Disease monitoring is done with periodic evaluation of clinical symptoms, markers of inflammation and imaging. The angiographic abnormalities do not disappear, but stop their progression with treatment [13].

TA is a chronic disease with a relapsing course [14]. Although the symptoms improve with glucocorticoid therapy, they tend to relapse once the dose is tapered 
off. Relapses have continued to occur in at least $50 \%$ of patients despite adjuvant immunosuppressive therapies or surgical revascularizations $[6,15]$.

TA is a granulomatous large vessel vasculitis with nonspecific symptoms at the outset, which can be easily overlooked. Unilateral clubbing is an extremely rare manifestation of TA. Therefore, detection of unilateral clubbing should raise a strong clinical suspicion of TA, with prompt diagnosis and initiation of treatment.

\section{Abbreviations}

TA: Takayasu's arteritis; ESR: Erythrocyte sedimentation rate; CRP: C- reactive protein; MRA: Magnetic resonance aortogram; ANA: Anti nuclear antibody; dsDNA: Double stranded DNA; pANCA: Perinuclear anti neutrophil cytoplasmic antibody; cANCA: Cytoplasmic anti neutrophil cytoplasmic antibody; PET: Positron emission tomography; PDGF: Platelet derived growth factor; VEGF: Vascular endothelial growth factor; HIF: Hypoxia inducible factor

\section{Acknowledgements}

The authors would like to acknowledge the team of radiology at National Hospital of Sri Lanka for their input in diagnosing the disease.

\section{Authors' contributions}

SNG collected information, followed up the patient, did literature review and drafted the manuscript. NW, CM, AJ and HK were involved in the diagnosis and management of the patient and preparing the manuscript. All the authors read and approved the final manuscript.

\section{Funding}

Not applicable.

\section{Availability of data and materials}

Not applicable.

\section{Ethics approval and consent to participate} Not applicable.

\section{Consent for publication}

Informed written consent for publishing the patient's details including the photos, in the journal was obtained from the patient by the corresponding author, and is available for the perusal of the editors upon request.

\section{Competing interests}

The authors declare that they have no competing interests.

Received: 22 June 2020 Accepted: 11 September 2020

Published online: 10 December 2020

\section{References}

1. Russo RAG, Katsicas MM. Takayasu arteritis. Front Pediatr. 2018;6:265.

2. Numano N, Fujio, et al. Takayasu's arteritis. Lancet. 2000;356(9234):1023-5.

3. Civilibal M, et al. A Takayasu's arteritis case with unilateral digital clubbing. Arch Rheumatol. 2011;26(2):163-6.

4. Kaditis AG, Nelson AM, Driscoll DJ. Takayasu's arteritis presenting with unilateral digital clubbing. J Rheumatol. 1995;22(12):2346.

5. Ishikawa M, Okada J, Kondo H. Takayasu's arteritis with transient clubbed finger. Clin Exp Rheumatol. 1999;17:629.

6. Comarmond C, et al. Long-term outcomes and prognostic factors of complications in Takayasu arteritis: a multicenter study of 318 patients. Circulation. 2017:136(12):1114-22.

7. Dejaco C, et al. EULAR recommendations for the use of imaging in large vessel vasculitis in clinical practice. Ann Rheum Dis. 2018:77(5):636-43.

8. Riera JL, Musuruana JL, Faccio F, Cavallasca JA. Constitutional symptoms, pathologic PET-CT. Cleve Clin J Med. 2020;87(4):195-7. https://doi.org/10. 3949/ccjm.87a.19053.

9. Arend WP, et al. The American College of Rheumatology 1990 criteria for the classification of Takayasu arteritis. Arthritis Rheum. 1990;33(8):1129-34.
10. Spicknall KE, Zirwas MJ, English JC III. Clubbing: an update on diagnosis, differential diagnosis, pathophysiology, and clinical relevance. J Am Acad Dermatol. 2005;52(6):1020-8.

11. Dickinson CJ, Martin JF. Megakaryocytes and platelet clumps are the cause of finger clubbing. Lancet. 1987;330(8573):1434-5.

12. Atkinson S, Fox SB. Vascular endothelial growth factor (VEGF)-a and plateletderived growth factor (PDGF) play a central role in the pathogenesis of digital clubbing. J Pathol. 2004;203(2):721-8.

13. Hellmich B, et al. 2018 update of the EULAR recommendations for the management of large vessel vasculitis. Ann Rheum Dis. 2020;79(1):19-30.

14. Maksimowicz-McKinnon K, Hoffman GS. Takayasu arteritis: what is the longterm prognosis? Rheum Dis Clin N Am. 2007;33(4):777-86.

15. Maksimowicz-McKinnon K, Clark TM, Hoffman GS. Limitations of therapy and a guarded prognosis in an American cohort of Takayasu arteritis patients. Arthritis Rheum. 2007;56(3):1000-9.

\section{Publisher's Note}

Springer Nature remains neutral with regard to jurisdictional claims in published maps and institutional affiliations.

\section{Ready to submit your research? Choose BMC and benefit from:}

- fast, convenient online submission

- thorough peer review by experienced researchers in your field

- rapid publication on acceptance

- support for research data, including large and complex data types

- gold Open Access which fosters wider collaboration and increased citations

- maximum visibility for your research: over $100 \mathrm{M}$ website views per year

At $\mathrm{BMC}$, research is always in progress.

Learn more biomedcentral.com/submissions 